\title{
KAJIAN TARIF JALAN TOL MEDAN-KUALANAMU-TEBING TINGGI
}

\author{
Amrizal \\ Prodi Teknik Perancang Jalan dan Jembatan \\ Jurusan Teknik Sipil, Politeknik Negeri Medan \\ Jln. Almamater No. 1, Kampus USU 20155, Medan \\ Amrizal.19750427@polmed.ac.id
}

\author{
Aldy Bashari \\ Prodi Teknik Perancang Jalan dan Jembatan \\ Jurusan Teknik Sipil, Politeknik Negeri Medan \\ Jln. Almamater No. 1, Kampus USU 20155, Medan \\ aldybashari@yahoo.co.id
}

\begin{abstract}
Medan-Kualanamu-Tebing Tinggi Toll Road is a series of toll roads that connect Medan City, Kuala Namu Airport, and Tebing Tinggi City. In this study, an analysis of the ability to pay and the willingness to pay of toll road users and financial analysis were performed to determine the feasibility of this toll road project. The analysis shows that the ability to pay and the willingness to pay of the toll road users reach the same value for a tariff of Rp600.00 per km. By using the current tariff, which is Rp1,000.00 per km, the project's capital return is estimated to occur in 2027. Meanwhile, if a tariff of Rp600.00 per km is applied, the toll road project is still financially viable, with a return on capital expected to occur in 2019.
\end{abstract}

Keywords: toll road, toll tariff, ability to pay, willingness to pay, financial analysis

\begin{abstract}
Abstrak
Jalan Tol Medan-Kualanamu-Tebing Tinggi adalah rangkaian jalan tol yang menghubungkan Kota Medan, Bandar Udara Kuala Namu, dan Kota Tebing Tinggi. Pada studi ini dilakukan analisis kemampuan membayar dan kerelaan membayar pengguna jalan tol tersebut serta analisis finansial untuk menentukan kelayakan proyek jalan tol ini. Hasil analisis menunjukkan bahwa kemampuan membayar dan kerelaan membayar pengguna jalan tol mencapai nilai yang sama untuk tarif sebesar Rp600,00 per km. Dengan menggunakan tarif yang berlaku saat ini, yaitu Rp1.000,00 per km, pengembalian modal proyek ini diperkirakan terjadi pada tahun 2027. Sementara itu, bila digunakan tarif sebesar Rp600,00 per km, proyek jalan tol ini masih layak secara finansial, dengan pengembalian modal diperkirakan terjadi pada tahun 2019.
\end{abstract}

Kata-kata kunci: jalan tol, tarif tol, kemampuan membayar, kerelaan membayar, analisis finansial

\section{PENDAHULUAN}

Kota Medan dan Kota Tebing Tinggi merupakan dua kota yang tak dapat dipisahkan dari sisi pengelolaan sistem transportasinya. Medan, sebagai ibu kota Provinsi Sumatera Utara, memiliki daya tarik luar biasa sebagai kawasan pengembangan ekonomi, karena kota ini merupakan pusat kegiatan-kegiatan sosial, ekonomi, dan politik. Sementara Tebing Tinggi merupakan kota transit di Jalan Lintas Timur Sumatera (Jalinsum). Di kota ini lalu lintas terpecah kedua arah, yaitu ke arah Kota Kisaran dan ke arah Kota Pematang Siantar. Saat ini, sebagian besar pelaku transportasi yang melintasi kedua kota tersebut menggunakan moda transportasi berbasis jalan dan sebagian lagi menggunakan moda rel. Infrastruktur jalan yang menghubungkan kedua kota tersebut terdiri atas Jalinsum, dengan fungsi arteri primer dengan Kelas Jalan I, serta Jalan Tol Medan-Kualanamu-Tebing Tinggi (MKTT), yang penggunaannya diresmikan pada akhir tahun 2017. 
Jalan Tol MKTT adalah suatu jalan tol yang menghubungkan Kota Medan, Bandara Kuala Namu, dan Kota Tebing Tinggi, yang dikelola oleh PT Jasa Marga. Jalan Tol MKTT ini diharapkan mampu memperbaiki kondisi lalu lintas di kawasan Medan-Tebing Tinggi melalui pembagian volume lalu lintas, dengan sebagian melewati Jalinsum dan sebagian melewati Jalan Tol MKTT. Jalan Tol MKTT ini juga diharapkan mampu mempersingkat waktu perjalanan para pengguna jalan dan meningkatkan aksesibilitas masyarakat menuju Bandara Kualanamu serta membantu upaya perbaikan tata guna lahan di Kawasan MedanTebing Tinggi (Amrizal, 2018).

Tujuan penelitian ini adalah: (1) menentukan nilai kemampuan membayar calon pengguna Jalan Tol MKTT; (2) menentukan nilai kerelaan membayar calon pengguna Jalan Tol MKTT; dan (3) melakukan analisis finansial terhadap tarif yang berlaku saat ini dan tarif berdasarkan kemampuan membayar dan kerelaan membayar pengguna jalan tol. Lingkup permasalahan penelitian ini dibatasi oleh beberapa hal, yaitu: (1) objek penelitian terbatas pada ruas Medan-Tebing Tinggi; (2) responden merupakan pengguna kendaraan bermotor Golongan I; (3) data didapat melalui survei kemampuan dan kerelaan membayar jalan tol; dan (4) penghematan waktu didasarkan pada selisih waktu tempuh penggunaan jalan tol dan jalan nontol.

Beberapa data diperlukan guna menunjang perhitungan kemampuan membayar (Ability to Pay, ATP) dan kerelaan membayar (Willingness to Pay, WTP) untuk penetapan tarif tol jalan tol. Data tersebut meliputi karakteristik sosial ekonomi calon pengguna jalan tol, variabel yang memengaruhi ATP, dan variabel yang memengaruhi WTP (Kanafani, 2003). Karena itu faktor-faktor yang digunakan untuk menentukan ATP terhadap jasa jalan tol adalah total pendapatan responden, alokasi pendapatan terhadap transportasi, dan alokasi biaya transportasi. Pendekatan yang digunakan dalam analisis WTP didasarkan pada tarif yang diharapkan. Variabel-variabel yang digunakan untuk menentukan WTP terhadap jasa jalan tol MKTT adalah tarif yang diharapkan dan kemauan membayar lebih untuk peningkatan keselamatan.

Karakteristik sosial ekonomi calon pengguna jalan tol ditunjukkan dalam kuisioner. Karakteristik ini meliputi umur, jenis kelamin, pendidikan terakhir, pekerjaan, pendapatan per bulan, pengeluaran untuk transportasi per bulan, kendaraan pribadi sehari-hari, jarak tempuh dalam satu hari, asal dan tujuan perjalanan, maksud perjalanan, serta frekuensi perjalanan dari Medan Kualanamu menuju ke Tebing Tinggi atau sebaliknya.

\section{ANALISIS DAN PEMBAHASAN}

\section{Ukuran Sampel}

Berdasarkan survei pendahuluan, dengan jumlah rata-rata kendaraan di setiap gerbang tol 20.575 kendaraan/hari dan dengan menggunakan tingkat kesalahan 5\%, didapat ukuran sampel sebanyak 392 (Israel, 2012; Sevilla, 2007). Pada penelitian ini, ukuran sampel yang digunakan adalah 400 responden. 


\section{Analisis Kerelaan dan Kerelaan Membayar Jalan Tol}

Berdasarkan survei yang telah dilakukan terhadap 400 responden, diperoleh informasi mengenai kemampuan dan kerelaan responden untuk membayar jalan tol.

Tabel 1 Kemampuan (ATP) dan Kerelaan (WTP) Respnden

\begin{tabular}{ccccc}
\hline \multicolumn{2}{c}{ ATP } & \multicolumn{2}{c}{ WTP } & $\begin{array}{c}\text { Tarif } \\
(\mathrm{Rp} / \mathrm{km})\end{array}$ \\
\cline { 1 - 4 } $13,50 \%$ & Responden & $(\%)$ & Responden & 850 \\
$24,25 \%$ & 54 & $10,00 \%$ & 40 & 650 \\
$26,75 \%$ & 107 & $23,75 \%$ & 95 & 450 \\
$35,50 \%$ & 142 & $28,75 \%$ & 115 & 300 \\
$100 \%$ & 400 & $37,50 \%$ & 150 & \\
\hline
\end{tabular}

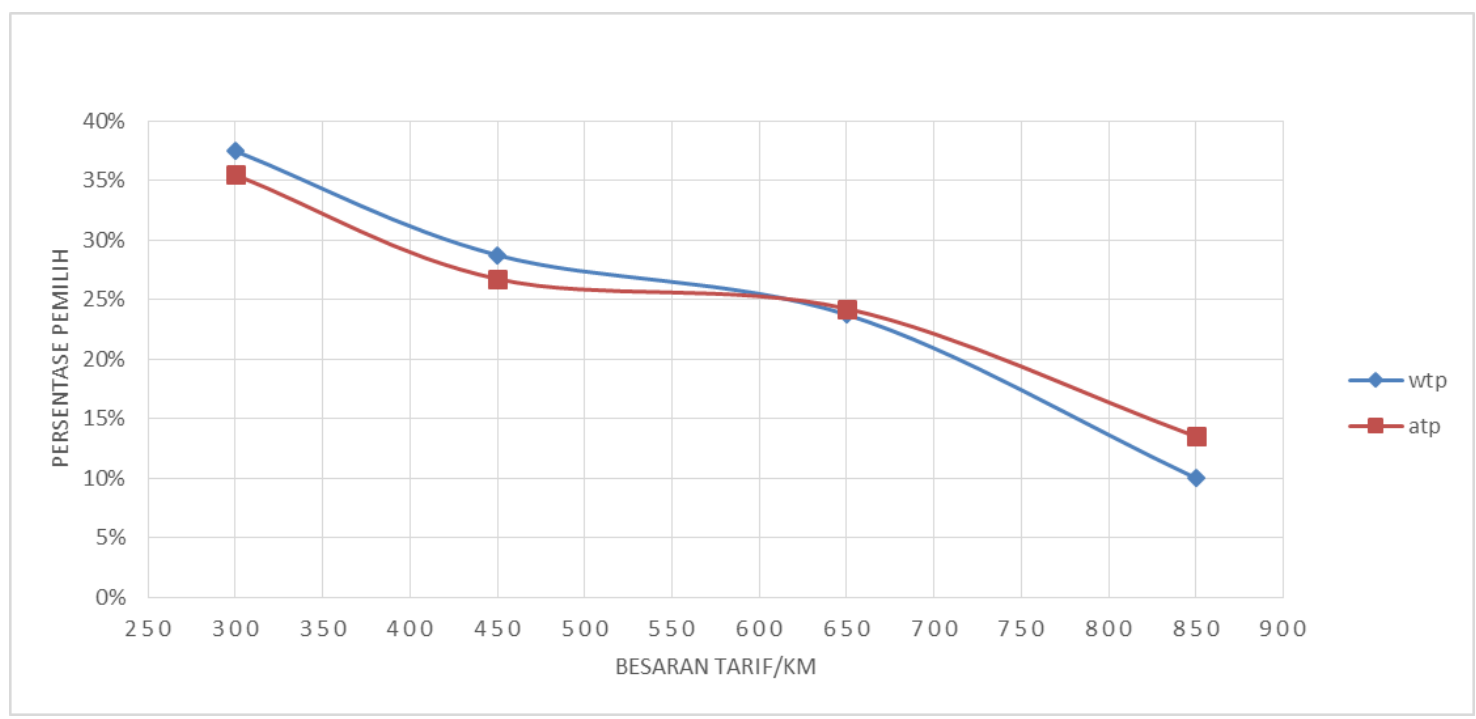

Gambar 1 Kemampuan (ATP) dan Kerelaan (WTP) Responden

Berdasarkan hasil survei, seperti yang ditunjukkan pada Tabel 1 dan Gambar 1, diketahui bahwa:

1) Pada tarif Rp850,00/km jumlah responden atau pengguna Jalan Tol MKTT responnya terhadap nilai ATP lebih kecil daripada nilai WTP. Hal ini berarti bahwa kemampuan membayar pengguna lebih kecil daripada kerelaan membayarnya.

2) Pada tarif Rp650,00/km jumlah responden atau pengguna Jalan Tol MKTT responnya terhadap nilai ATP lebih kecil daripada nilai WTP, yang berarti kemampuan membayar pengguna lebih kecil daripada kerelaan membayarnya.

3) Pada tarif Rp600,00/km jumlah responden atau pengguna Jalan Tol MKTT terhadap responnya nilai ATP sama dengan nilai WTP. Hal ini berarti kemampuan membayar pengguna sama dengan kerelaan membayarnya. Nilai ini nantinya akan menjadi pembanding terhadap tarif yang berlaku saat ini, yaitu Rp1.000,00/km, untuk digunakan pada analisis dari sisi finansial. 
4) Pada tarif Rp450,00/km jumlah responden atau pengguna Jalan Tol MKTT terhadap nilai ATP lebih besar daripada nilai WTP. Kondisi ini berarti bahwa kemampuan membayar pengguna lebih besar daripada kerelaan membayarnya.

Analisis pada studi ini dilakukan melalui 3 tahapan, yaitu: (1) proses estimasi biaya ekonomi/finansial (biaya konstruksi, operasi, dan pemeliharaan) (2) proses estimasi manfaat ekonomi dan pendapatan finansial yang dihasilkan dari analisis dengan dan tanpa proyek selama waktu tinjauan, dan (3) proses analisis kelayakan dengan menggunakan sejumlah indikator kelayakan, seperti Net Present Value (NPV), dan Benefit Cost Ratio (BCR), dan Financial Rate of Return (FIRR). Pada Tabel 2 ditampilkan hasil perhitungan indikatorindikator kelayakan finansial Jalan Tol MKTT dengan menggunakan tarif sebesar Rp1.000,00/km.

Tabel 2 Indikator Kelayakan Finansial Jalan Tol MKTT pada Tarif Rp1.000,00/km

\begin{tabular}{lccc}
\hline \multirow{2}{*}{ Ukuran Kelayakan Ekonomi } & \multicolumn{3}{c}{ Discount Rate } \\
\cline { 2 - 4 } & $12,0 \%$ & $17,0 \%$ & $22,0 \%$ \\
\hline Net Present Value-NVP (Juta Rp) & 4.764 .890 & 246.206 & -1.470 .292 \\
Benefit Cost Ratio-BCR & 2,06 & 1,06 & 0,65 \\
Finansial Internal Rate of Return-FIRR (\%) & \multicolumn{3}{c}{$17,72 \%$} \\
\hline
\end{tabular}

\section{Tingkat Finansial pada Tarif Permintaan}

Indikator finansial yang digunakan pada studi ini adalah Net Present Value (NPV), Benefit Cost Ratio (BCR), dan Financial Internal Rate of Return (FIRR). Perhitungan analisis finansial juga memperhitungkan pendapatan-pendapatan di luar tarif. Pendapatan nontarif ini diperoleh dari pendapatan iklan, yang meliputi pemasangan iklan di depan gerbang tol dan di Jalan Tol MKTT. Hasil perhitungan indikator kelayakan finansial Jalan Tol MKTT dengan menggunakan tarif Rp600,00/km dapat dilihat pada Tabel 3.

Tabel 3 Indikator Kelayakan Finansial Jalan Tol MKTT pada Tarif Rp600,00/km

\begin{tabular}{llll}
\hline \multirow{2}{*}{ Ukuran Kelayakan Finansial } & \multicolumn{3}{l}{ Discount Rate } \\
\cline { 2 - 4 } & $5,0 \%$ & $10,0 \%$ & $15,0 \%$ \\
\hline Net Present Value-NPV (Juta Rp) & 10.818 .525 & 2.009 .836 & -815.601 \\
Benefit Cost Ratio-BCR & 3,20 & 1,44 & 0,81 \\
Finansial Internal Rate of Return-FIRR (\%) & $13,56 \%$ & & \\
\hline
\end{tabular}

Hasil analisis finansial dengan menggunakan tarif Rp600,00/km adalah NPV sebesar Rp2.009.836.000.000,00 dan BCR bernilai 1,44 pada discount rate 10\% serta nilai FIRR sebesar 13,56\%. Hasil perhitungan ini menunjukkan bahwa dengan nilai tarif Rp600,00/km pembangunan Jalan Tol MKTT masih layak secara finansial.

\section{Hasil Analisis Break Event Point}

Analisis kelayakan pengusahaan prasarana umum terkait dengan perbandingan besaran biaya dan besaran pendapatan yang akan diperoleh oleh pengusaha prasarana. Dalam 
berbagai kajian untuk prasarana umum, analisis kelayakan biasanya dilakukan dengan menggunakan metode atau indikator BE, untuk menyatakan kelayakan pengusahaan.

Hasil analisis menunjukkan bahwa dengan menggunakan tarif Rp1.000,00 per km, BEP diperkirakan terjadi pada tahun 2027. Pada Gambar 2 dapat dilihat BEP yang terjadi dengan menggunakan tarif sebesar Rp1.000,00 per km.

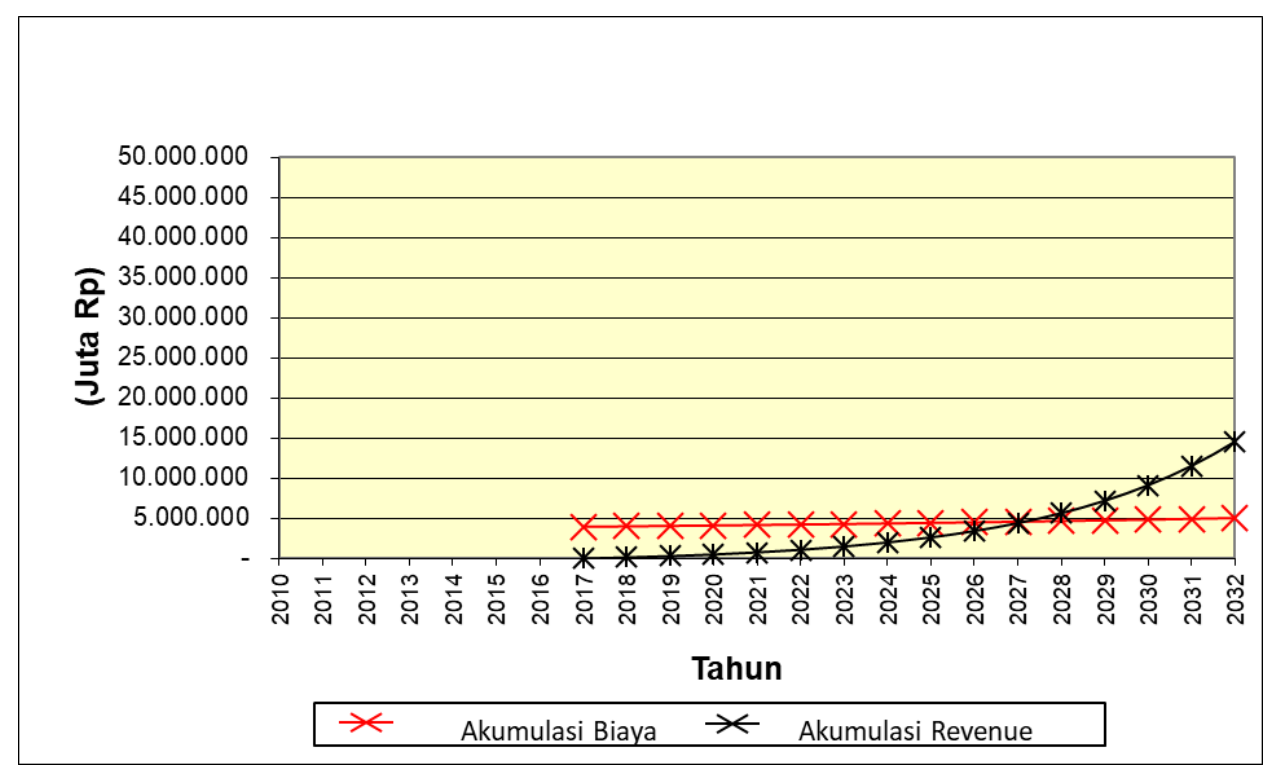

Gambar 2 BEP untuk Tarif Rp1.000,00/km

Bila digunakan tarif sebesar Rp600,00 per km, hasil analisis menunjukkan bahwa BEP akan terjadi pada tahun 2029. Gambar 3 menunjukkan BEP yang terjadi bila digunakan tarif sebesar Rp600,00 per km.

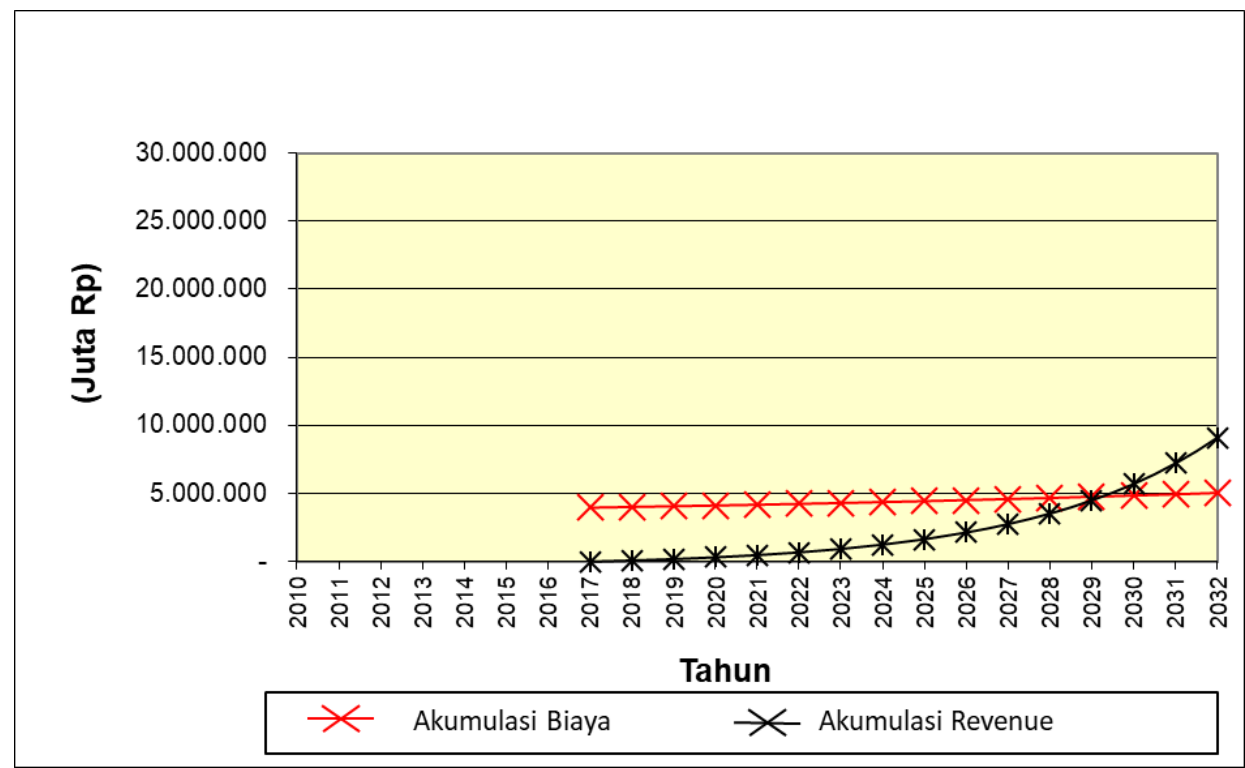

Gambar 3 BEP untuk Tarif Rp600,00/km 


\section{KESIMPULAN}

Dari kajian ini dapat ditarik kesimpulan sebagai berikut:

1) Pada tarif Rp600,00/km diperoleh nilai ATP sama dengan nilai WTP, yang berarti kemampuan membayar pengguna Jalan Tol MKTT sama dengan kerelaan membayarnya. Dengan menggunakan nilai tarif ini, BEP proyek Jalan Tol MKTT diperkirakan terjadi pada tahun 2029.

2) Hasil analisis finansial terhadap proyek Jalan Tol MKTT, dengan menggunakan tarif sebesar Rp600/km, menunjukkan bahwa proyek Jalan Tol MKTT masih layak untuk dilaksanakan.

\section{DAFTAR PUSTAKA}

Amrizal. 2018. Potensi dan Kendala Pengembangan Angkutan Umum Pariwisata Kawasan Toba. (Online), (http://jurnal.abulyatama.ac.id/tekniksipil8unaya/article/view/195).

Israel, G.D. 2012. Determining Sample Size, PEOD6. Agricultural Education dan Communication Department, Florida Cooperative Extension Service, Institute of Food dan Agricultural Sciences, University of Florida, Gainesville, FL.

Kanafani, A.K. 2003. Transportation Demand Analysis. New York, NY: McGraw Hill.

Sevilla, C.G., Ochave, J.A., Punsalan, T.G., Regala, B.P., dan Uriarte, G.G. 2007. Research Methods. Quezon City: Rex Printing Company. 